\title{
Outcomes of patients with chronic obstructive pulmonary disease diagnosed with or without pulmonary function testing
}

\author{
Andrea Gershon MD MSc, Graham Mecredy MSc, Ruth Croxford MSc, Teresa To PhD, \\ Matthew B. Stanbrook MD PhD, Shawn D. Aaron MD; for the Canadian Respiratory Research Network
}

Cite as: CMAJ 2017 April 10;189:E530-8. doi: 10.1503/cmaj.151420

\begin{abstract}
BACKGROUND: A small number of people with chronic obstructive pulmonary disease (COPD) receive pulmonary function testing around the time of diagnosis. Because omitting testing increases misdiagnosis, we sought to determine whether health outcomes differed between patients whose COPD was diagnosed with or without pulmonary function testing.
\end{abstract}

METHODS: We conducted a longitudinal population study of patients with physician-diagnosed COPD from 2005 to 2012 using health administrative data from Ontario, Canada. We assessed whether having pulmonary function testing around the time of diagnosis was associated with the composite outcome of admission to hospital for COPD or all-cause death, using adjusted survival analysis.

RESULTS: Chronic obstructive pulmonary disease was diagnosed in 68898 patients during the study period; $41.2 \%$ of patients received peridiagnostic pulmonary function testing. In adjusted analysis, patients who underwent testing were less likely to die or be admitted to hospital for COPD (adjusted hazard ratio [HR] 0.91, 95\% confidence interval [Cl] 0.89-0.94) and were more likely to be prescribed an inhaled long-acting bronchodilator than patients who did not undergo testing. Subgroup analysis suggested that the association of testing and outcomes was confined to patients with COPD diagnosed in the ambulatory care setting (adjusted HR $0.80,95 \% \mathrm{Cl}$ 0.76-0.84).

INTERPRETATION: Confirmation of a COPD diagnosis using pulmonary function testing is associated with a decreased risk of death and admission to hospital for COPD. In ambulatory patients, this effect may be from increased use of appropriate COPD medications. The findings of this study validate current guideline recommendations that encourage pulmonary function testing for diagnosis in all patients with suspected COPD. hronic obstructive pulmonary disease (COPD) is the third leading cause of death, a leading cause of hospital admission and affects more than $10 \%$ of adults. ${ }^{1-3}$ Pulmonary function testing plays a fundamental role in COPD diagnosis by confirming persistent airflow obstruction and ruling out other diseases. However, despite recommendations that all patients with suspected COPD undergo pulmonary function testing, only $30 \%$ to $50 \%$ of patients with physician-diagnosed COPD do..$^{3-9}$ Thus, the diagnosis and subsequent management of COPD appears to be largely based on clinical assessment - despite the frequency of misdiagnosis that occurs. ${ }^{10}$ Although a lack of pulmonary function testing has been associated with suboptimal prescribing, smoking cessation and specialist referral, ${ }^{11-15}$ studies showing better patient outcomes are lacking. This gap has been used by some physicians to justify not ordering testing., 516
We conducted the current study to determine if obtaining pulmonary function testing for suspected COPD was associated with improved health outcomes.

\section{Methods}

We conducted a longitudinal population study from 2005 to 2012 using health administrative data from Ontario, Canada.

\section{Data sources}

Residents of Ontario have universal public health insurance for all medically necessary services. Details are captured in large health administrative databases: the Registered Persons Database provides demographic information and date of death; the Canadian Institute of Health Information Discharge Abstract 
Database and National Ambulatory Care Reporting System Databases contain hospital admission and emergency department visit information, respectively; the Ontario Health Insurance Plan Physician Claims database provides information about physician services; the Ontario Drug Benefit Program database contains prescription claim records for all residents aged 65 years or older that are subject to a small copayment, which does not affect the rate they are obtained; ${ }^{17}$ the Institute for Clinical Evaluative Sciences (ICES) Physician Database contains information on all physicians. These data sets were individually linked using unique encoded identifiers and analyzed at ICES.

The 2001, 2003, 2005 and 2007/8 national, population-based Canadian Community Health Surveys provided additional information, including smoking history, for the patients who participated in the survey.

\section{Study population}

Physician-diagnosed COPD is an imperfect measure of COPD likely, at least in part, because not all patients receive pulmonary function testing. ${ }^{8,18}$ All patients aged 43 and older with physiciandiagnosed COPD between 2005 and 2012 were identified using a previously validated case-definition of physician-diagnosed COPD: age 35 years and older, and 1 or more COPD-related hospital admission or 3 or more physician COPD ambulatory care visits within 2 years. ${ }^{19,20}$ This case definition has a specificity of $95 \%$ and a positive predictive value of $81 \%$ compared with a clinical reference standard (which may or may not have considered pulmonary function testing). ${ }^{19}$ Although the exact COPD diagnoses dates are not available from the data, because COPD is a disease with insidious onset, it was presumed that patients likely had COPD as per the earliest of these health service encounters. The start of follow-up (the study index date) was the latest health service encounter that was used to identify patients with COPD to avoid immortal time. A minimal 5-year look-back period ensured that COPD was newly diagnosed (Figure 1). Ages 43 years and older were studied to allow a sufficient look-back period to measure guideline-based care (Table 1). Patients were excluded if they were ineligible for health insurance, if they died during their stay in hospital, if they had previous lung volume reduction surgery or lung transplant or if their primary care physician demographic data were missing.

\section{Exposure}

The primary exposure was empiric use of pulmonary function testing around the time of diagnosis, which was defined as a period extending from 1 year before the earliest health service encounter to the latest encounter (the index date) that identified a patient's disease (Figure 1). ${ }^{8}$ Pulmonary function testing was generously defined as spirometry before or after bronchodilation and could have been performed in any location.

\section{Baseline characteristics}

We obtained demographic, COPD-related and general carerelated characteristics from health administrative data. Patient socioeconomic status was derived ecologically using the patient's residential postal code. ${ }^{23}$ Rural or urban residence was determined according to Statistics Canada definitions. ${ }^{24}$ Comorbidities were grouped using the Johns Hopkins Adjusted Clinical Group CaseMix System. ${ }^{21}$ Characteristics of patients' primary care physicians were considered because they were most responsible for arranging pulmonary function testing. Physician propensity for quality care was determined using the proportion of eligible patients who received glucose or cholesterol testing in the last 3 years - a continuous variable with a higher proportion suggesting better quality care..$^{25,26}$ Pulmonary function testing after the peridiagnostic period was also considered - if it occurred more than once, only the first instance was counted.

\section{Outcome measures}

The primary outcome was a composite of COPD-related hospital admission or all-cause death. All-cause death was used because COPD is underestimated by about $50 \%$ as a cause of death in vital statistics records. ${ }^{27,28}$

\section{Statistical analysis}

Outcomes were analyzed using Cox proportional hazards regression analysis. To compare patients with similar observed characteristics, the propensity for each patient to receive pulmonary function testing was calculated using logistic regression and all covariables (see Table 1). This propensity score was then used as a covariate in the survival analyses to estimate the effect of testing on the outcomes of interest. Full details on the calculation and use of propensity scores to address bias in observational studies is provided elsewhere..$^{29}$ Pulmonary function testing after the peridiagnostic period was the only time-varying covariable. To account for the possibility that physicians more likely to order testing were also more likely to provide better quality care all round, we clustered patients by their primary care physicians and adjusted for other markers of good quality care. To see if results differed by age, sex, a codiagnosis of asthma or diagnosis with COPD in the ambulatory or hospital setting, we tested the significance of interaction terms between each of these and pulmonary function testing. Analyses were performed using SAS version 9.3 (SAS Institute Inc., Cary, North Carolina).

\section{Sensitivity analyses}

Propensity score matching was performed. ${ }^{29}$ However, this was not used as the primary analysis because it could not accommodate the time-varying covariate. To account for variables not available in the data, such as smoking, propensity score calibration was used. In brief, gold-standard propensity scores, one for each of the representative subcohort of people who had additional data from the Canadian Community Health Survey, were compared with original propensity scores. The relative difference was used to calibrate the propensity scores of the rest of the participants. Analysis for patients aged 67 years and older (for whom we had 2 years of look back for medication) was conducted to exclude patients who might have had earlier unrecorded COPD - as evident by them receiving a COPD medication - and to adjust for previous medication use. Finally, we determined whether it was plausible that an unmeasured confounder or misclassification could account for the results using 
methods described elsewhere. ${ }^{30}$ Details of all sensitivity analyses are in available in Appendix 1 (available at www.cmaj.ca/ lookup/suppl/doi:10.1503/cmaj.151420/-/DC1).

\section{Process of care}

The association of pulmonary function testing and medication use was examined in patients aged 67 years and older. Medications received were compared before and after testing or an equivalent date between patients receiving and not receiving testing (see Appendix 1). This analysis was done in the propensity score- matched group.

\section{Ethics approval}

Ethics committee approval was obtained from Sunnybrook Health Sciences Centre, Toronto, Ontario.

\section{Results}

A total of 68898 patients had a diagnosis of COPD, of whom $41.2 \%$ received pulmonary function testing (Table 1 and Appendix 1). Patients who received testing were younger, more likely to have seen a specialist, less likely to have comorbidities and more likely to be cared for by a primary physician who practised guidelinebased care (Table 1 ).

In unadjusted analyses, fewer patients who received pulmonary function testing had a COPD-related hospital admission or died of any cause compared with patients who did not.

In adjusted analyses, patients with COPD who received pulmonary function testing were $9 \%$ less likely be admitted to hospital for COPD or to die of any cause than those who did not (hazard ratio [HR] 0.91, 95\% confidence interval [Cl] 0.89-0.94) (Table 2).
There was no evidence that the association between peridiagnostic pulmonary function testing and COPD hospital admission or death from any cause differed by sex $(p=0.87)$ or asthma status ( $p=0.22$ ); however, it differed by whether patients received their diagnosis in the ambulatory care or hospital setting $(p<0.001)$ and by age $(p=0.003)$. Among patients who received their diagnosis while ambulatory, pulmonary function testing was associated with a significantly reduced risk of COPDrelated hospital admission or death from any cause across all age groups, whereas among those who received their diagnosis while in hospital, testing was associated with a modest but significantly increased risk of these events (Table 2, Figure 2). Because it seemed apparent that the former was an important distinction, further analyses were done taking this division into account (Appendix 1).

\section{Sensitivity analysis}

Propensity score matching (which achieved no clinically meaningful differences in baseline variables between those receiving and not receiving testing) and calibrated propensity score analysis (which accounted for smoking and other variables not available in the health administrative data) produced results similar to the main results. Only under very unlikely assumptions would an unmeasured confounder or misclassification account for the results observed among patients who received their diagnosis in the ambulatory care setting (Appendix 1). As expected, in the analysis of data from patients aged 67 years and older, which adjusted for medication use - a process of care on the causal pathway to all the outcomes - the association between testing and death or hospital admission for COPD no longer reached statistical significance.

Accrual window for patients with newly diagnosed COPD

(September 2005 to March 2012)

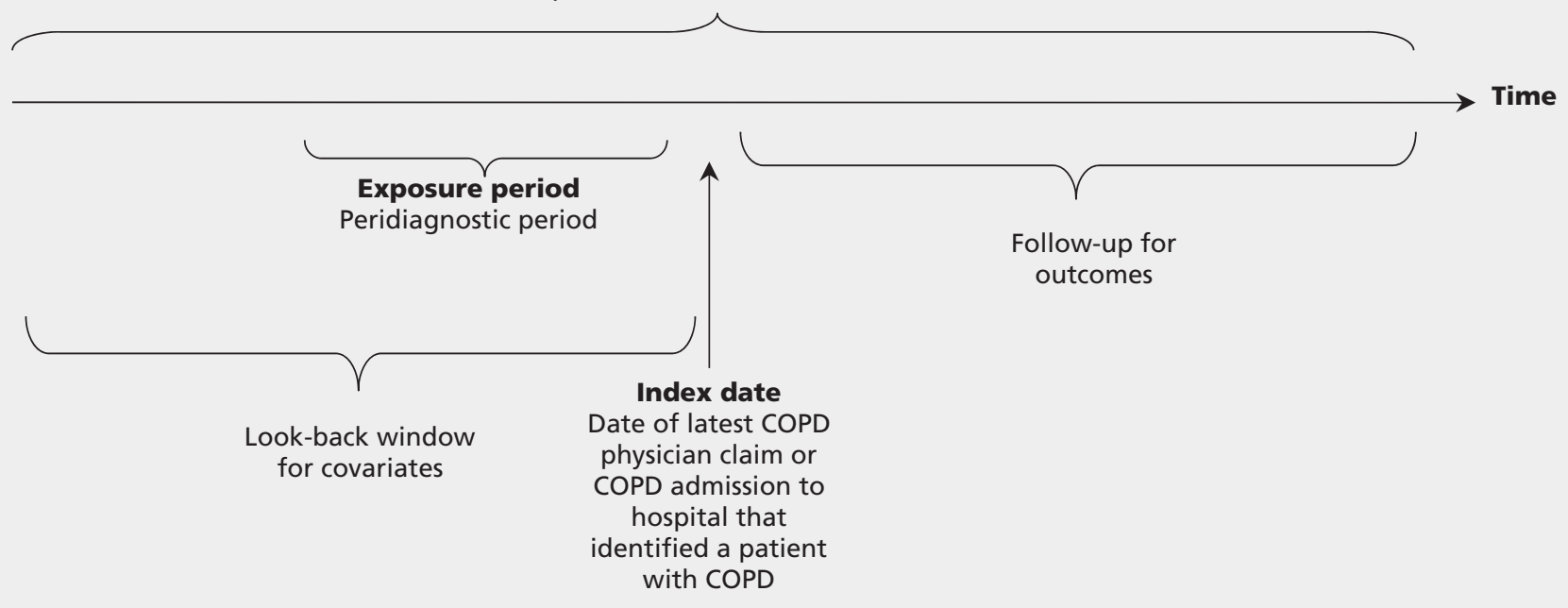

Figure 1: Study design. $\mathrm{COPD}=$ chronic obstructive pulmonary disease. 
Table 1 (part 1 of 2): Selected baseline characteristics, before and after propensity score matching, of patients with physician-diagnosed COPD who did and did not receive pulmonary function testing in the peridiagnostic period*

\begin{tabular}{|c|c|c|c|c|c|c|c|c|}
\hline \multirow[b]{3}{*}{ Characteristic } & \multicolumn{4}{|c|}{ Before propensity score matching } & \multicolumn{4}{|c|}{ After propensity score matching } \\
\hline & \multicolumn{2}{|c|}{$\begin{array}{l}\text { Testing in peridiagnostic } \\
\text { period }\end{array}$} & \multirow{2}{*}{$\begin{array}{l}\text { Standardized } \\
\text { difference, \% }\end{array}$} & \multirow[b]{2}{*}{$p$ value $†$} & \multicolumn{2}{|c|}{$\begin{array}{l}\text { Testing in peridiagnostic } \\
\text { period }\end{array}$} & \multirow{2}{*}{$\begin{array}{l}\text { Standardized } \\
\text { difference, \% }\end{array}$} & \multirow[b]{2}{*}{$p$ valuet } \\
\hline & Yes & No & & & Yes & No & & \\
\hline Patients, $n$ & 28386 & 40512 & & & 17783 & 17783 & & \\
\hline \multicolumn{9}{|l|}{ Demographic characteristics } \\
\hline Age, yr, mean $\pm S D$ & $66.86 \pm 11.53$ & $70.27 \pm 13.31$ & 0.3 & $<0.001$ & $67.20 \pm 11.87$ & $67.20 \pm 11.88$ & 0.00 & 1.0 \\
\hline Women, \% & 47.4 & 49.4 & 0.04 & $<0.001$ & 47.4 & 47.4 & 0.00 & 1.0 \\
\hline \multicolumn{9}{|l|}{ Income quintile, \% } \\
\hline 1 (lowest) & 22.6 & 25.7 & 0.07 & $<0.001$ & 24.1 & 24.2 & 0.00 & 0.9 \\
\hline 2 & 21.5 & 22.3 & 0.02 & & 22.2 & 22.4 & 0.01 & \\
\hline 3 & 19.8 & 19.3 & 0.01 & & 19.8 & 19.5 & 0.01 & \\
\hline 4 & 18.7 & 17.4 & 0.03 & & 18.0 & 17.8 & 0.00 & \\
\hline 5 (highest) & 17.4 & 15.4 & 0.05 & & 16.0 & 16.1 & 0.00 & \\
\hline Rural (v. urban) residence, $\%$ & 13.1 & 17.9 & 0.1 & $<0.001$ & 15.3 & 15.9 & 0.01 & 0.2 \\
\hline Immigrant, \% & 7.3 & 6.5 & 0.03 & $<0.001$ & 7.2 & 7.2 & 0.00 & 0.9 \\
\hline Living in long-term care, \% & 0.9 & 7.9 & 0.3 & $<0.001$ & 1.3 & 1.2 & 0.01 & 0.3 \\
\hline \multicolumn{9}{|l|}{ COPD-related characteristics, \% } \\
\hline $\begin{array}{l}\text { Ambulatory during the peridiagnostic } \\
\text { period }\end{array}$ & 70.5 & 43.7 & 0.6 & $<0.001$ & 62.6 & 62.6 & 0.00 & 1.0 \\
\hline \multicolumn{9}{|l|}{ Spirometry before peridiagnostic period } \\
\hline Up to $1 \mathrm{yr}$ before & 13.4 & 5.2 & 0.30 & $<0.001$ & 8.4 & 8.3 & 0.00 & 1.0 \\
\hline More than $1-2 \mathrm{yr}$ before & 5.6 & 3.8 & 0.09 & & 4.9 & 5.0 & 0.00 & \\
\hline More than 2-5 yr before & 10.3 & 7.9 & 0.08 & & 9.6 & 9.7 & 0.00 & \\
\hline More than $5 \mathrm{yr}$ before or never & 70.7 & 83.1 & 0.30 & & 77.1 & 77.0 & 0.00 & \\
\hline Pulmonologist visit in previous year $\ddagger$ & 26.8 & 2.9 & 0.8 & $<0.001$ & 6.5 & 5.7 & 0.03 & 0.004 \\
\hline $\begin{array}{l}\text { Internal medicine or geriatrics specialist } \\
\text { visits in previous year }\end{array}$ & 51.0 & 35.2 & 0.3 & $<0.001$ & 44.9 & 43.6 & 0.03 & 0.01 \\
\hline Long-term oxygen therapy & 2.9 & 1.5 & 0.1 & $<0.001$ & 1.6 & 1.5 & 0.01 & 0.6 \\
\hline \multicolumn{9}{|l|}{ General health characteristics } \\
\hline $\begin{array}{l}\text { Primary care physician visits in previous } \\
\text { year, median (IQR) } \ddagger\end{array}$ & $7(4-11)$ & $7(4-11)$ & 0.05 & $<0.001$ & $7(4-11)$ & $6(4-11)$ & 0.03 & $<0.001$ \\
\hline Influenza vaccination, $\%$ & 48.6 & 42.9 & 0.1 & $<0.001$ & 45.9 & 46.4 & 0.01 & 0.3 \\
\hline \multicolumn{9}{|c|}{ Previous or coexisting medical conditions, $\%$} \\
\hline Asthma & 29.4 & 19.7 & 0.2 & $<0.001$ & 23.5 & 23.5 & 0.00 & 1 \\
\hline Other chronic respiratory disease & 17.5 & 8.2 & 0.3 & $<0.001$ & 6.4 & 5.7 & 0.03 & 0.008 \\
\hline Lung cancer & 8.9 & 4.0 & 0.2 & $<0.001$ & 11.3 & 10.6 & 0.02 & 0.04 \\
\hline Pulmonary embolism & 2.7 & 2.9 & 0.01 & 0.3 & 2.6 & 2.4 & 0.01 & 0.4 \\
\hline Cor pumonale & 0.1 & 0.0 & 0.02 & 0.007 & 0.1 & 0.0 & 0.01 & 0.3 \\
\hline Acute myocardial infarction & 30.2 & 34.1 & 0.08 & $<0.001$ & 30.3 & 30.3 & 0.00 & 0.9 \\
\hline Other ischemic heart disease & 24.7 & 26.8 & 0.05 & $<0.001$ & 24.5 & 24.3 & 0.00 & 0.8 \\
\hline Congestive heart failure & 19.6 & 26.4 & 0.2 & $<0.001$ & 20.6 & 20.1 & 0.01 & 0.2 \\
\hline Dementia & 5.4 & 15.3 & 0.3 & $<0.001$ & 6.2 & 7.2 & 0.04 & $<0.001$ \\
\hline Arrhythmias & 21.5 & 25.2 & 0.09 & $<0.001$ & 21.7 & 21.1 & 0.02 & 0.2 \\
\hline Cerebrovascular disease & 11.0 & 17.6 & 0.2 & $<0.001$ & 12.4 & 12.2 & 0.00 & 0.7 \\
\hline Osteoporosis & 2.2 & 4.2 & 0.1 & $<0.001$ & 2.4 & 2.4 & 0.01 & 0.6 \\
\hline \multicolumn{9}{|l|}{ Psychiatric disease } \\
\hline Requiring hospital admission & 0.7 & 1.7 & 0.09 & $<0.001$ & 0.9 & 0.9 & 0.00 & 0.8 \\
\hline Requiring ambulatory care visits & 9.3 & 9.5 & 0.01 & & 8.9 & 8.9 & 0.00 & \\
\hline
\end{tabular}


Table 1 (part 2 of 2): Selected baseline characteristics, before and after propensity score matching, of patients with physician-diagnosed COPD who did and did not receive pulmonary function testing in the peridiagnostic period*

\begin{tabular}{|c|c|c|c|c|c|c|c|c|}
\hline \multirow[b]{3}{*}{ Characteristic } & \multicolumn{4}{|c|}{ Before propensity score matching } & \multicolumn{4}{|c|}{ After propensity score matching } \\
\hline & \multicolumn{2}{|c|}{$\begin{array}{l}\text { Testing in peridiagnostic } \\
\text { period }\end{array}$} & \multirow{2}{*}{$\begin{array}{l}\text { Standardized } \\
\text { difference, \% }\end{array}$} & \multirow[b]{2}{*}{$p$ valuet } & \multicolumn{2}{|c|}{$\begin{array}{c}\text { Testing in peridiagnostic } \\
\text { period }\end{array}$} & \multirow{2}{*}{$\begin{array}{l}\text { Standardized } \\
\text { difference, \% }\end{array}$} & \multirow[b]{2}{*}{$p$ value } \\
\hline & Yes & No & & & Yes & No & & \\
\hline \multicolumn{9}{|c|}{ Previous or coexisting medical conditions, $\%$} \\
\hline None & 90.0 & 88.8 & 0.04 & & 90.2 & 90.3 & 0.01 & \\
\hline Palliative & 1.2 & 2.1 & 0.06 & $<0.001$ & 1.3 & 1.3 & 0.00 & 0.7 \\
\hline \multicolumn{9}{|l|}{ Overall level of comorbidity§ } \\
\hline High & 30.4 & 28.4 & 0.04 & $<0.001$ & 27.2 & 26.5 & 0.02 & 0.2 \\
\hline Medium & 43.3 & 40.4 & 0.06 & & 42.2 & 42.2 & 0.02 & \\
\hline Low & 26.3 & 31.2 & 0.11 & & 30.6 & 31.3 & 0.02 & \\
\hline \multicolumn{9}{|l|}{ Recent acute events, $\%$} \\
\hline \multicolumn{9}{|c|}{ Most recent admission for acute bronchitis, pneumonia or influenza } \\
\hline In the past $6 \mathrm{mo}$ & 2.4 & 3.2 & 0.05 & $<0.001$ & 2.3 & 2.1 & 0.01 & 0.09 \\
\hline$>6$ mo before index date & 4.6 & 6.2 & 0.07 & & 4.6 & 4.2 & 0.02 & \\
\hline Never & 93.0 & 90.6 & 0.09 & & 93.2 & 93.7 & 0.02 & \\
\hline \multicolumn{9}{|l|}{ Most recent admission for asthma } \\
\hline In the past 6 mo & 0.5 & 0.2 & 0.05 & $<0.001$ & 0.3 & 0.3 & 0.00 & 0.2 \\
\hline$>6$ mo before index date & 1.0 & 0.7 & 0.03 & & 0.8 & 0.7 & 0.02 & \\
\hline Never & 98.5 & 99.1 & 0.06 & & 98.9 & 99.1 & 0.02 & \\
\hline \multicolumn{9}{|c|}{ Most recent admission for other respiratory disease } \\
\hline In the past $6 \mathrm{mo}$ & 1.6 & 1.2 & 0.03 & $<0.001$ & 0.7 & 0.7 & 0.00 & 0.7 \\
\hline$>6$ mo before index date & 2.3 & 1.5 & 0.06 & & 1.6 & 1.5 & 0.01 & \\
\hline Never & 96.1 & 97.2 & 0.06 & & 97.8 & 97.9 & 0.01 & \\
\hline \multicolumn{9}{|c|}{ Most recent emergency department visit for acute bronchitis, pneumonia or influenza } \\
\hline In the past 6 mo & 3.6 & 3.9 & 0.02 & $<0.001$ & 3.8 & 3.7 & 0.01 & 0.5 \\
\hline$>6$ mo before index date & 8.2 & 7.6 & 0.02 & & 8.1 & 7.8 & 0.01 & \\
\hline Never & 88.2 & 88.4 & 0.01 & & 88.1 & 88.5 & 0.01 & \\
\hline \multicolumn{9}{|c|}{ Most recent emergency department visit for asthma } \\
\hline In the past 6 mo & 1.4 & 0.9 & 0.05 & $<0.001$ & 1.3 & 1.2 & 0.01 & 0.9 \\
\hline$>6$ mo before index date & 2.8 & 1.9 & 0.06 & & 2.4 & 2.4 & 0.00 & \\
\hline Never & 95.7 & 97.2 & 0.08 & & 96.3 & 96.4 & 0.01 & \\
\hline \multicolumn{9}{|c|}{ Most recent emergency department visit for other respiratory disease } \\
\hline In the past 6 mo & 0.6 & 0.4 & 0.02 & $<0.001$ & 0.4 & 0.4 & 0.00 & 0.7 \\
\hline$>6$ mo before index date & 0.7 & 0.4 & 0.04 & & 0.4 & 0.4 & 0.01 & \\
\hline \multicolumn{9}{|l|}{ Primary care physician characteristics } \\
\hline Age, yr, mean \pm SD & $52.87 \pm 10.33$ & $53.61 \pm 10.23$ & 0.07 & $<0.001$ & $52.99 \pm 10.40$ & $53.10 \pm 10.19$ & 0.01 & 0.3 \\
\hline Women, \% & 23.4 & 18.8 & 0.11 & $<0.001$ & 21.3 & 21.4 & 0.00 & 0.8 \\
\hline $\begin{array}{l}\text { Graduated from a Canadian medical } \\
\text { school, } \%\end{array}$ & 75.6 & 76.0 & 0.01 & 0.3 & 75.5 & 75.5 & 0.00 & 1.0 \\
\hline Continuity of care index, $\boldsymbol{\uparrow}$ median (IQR) & $1(1-1)$ & $1(1-1)$ & 0.03 & 0.02 & $1(1-1)$ & $1(1-1)$ & 0.01 & 0.7 \\
\hline \multicolumn{9}{|l|}{ Quality of care measures, $\%$} \\
\hline Glucose testing in previous $3 \mathrm{yr}$ & 88.8 & 83.4 & 0.15 & $<0.001$ & 86.5 & 86.6 & 0.00 & 0.8 \\
\hline Cholesterol testing in previous $3 \mathrm{yr}$ & 79.4 & 68.6 & 0.24 & $<0.001$ & 76.1 & 76.7 & 0.01 & 0.3 \\
\hline
\end{tabular}




\section{Processes of care}

There were 16798 patients aged 67 years and older with newly diagnosed COPD. Patients who were not already taking an inhaled long-acting bronchodilator or long-acting $\beta$-agonist- inhaled corticosteroid combination were significantly more likely to have those medications added to their treatment regimen if they were in the testing as opposed to the non-testing group $(p<0.001)$. The same increase in medication use was not observed with inhaled corticosteroids $(p=0.040)$ (Table 3$)$.

\section{Interpretation}

We examined the association between pulmonary function testing and important patient outcomes in a large, complete, real-world population of patients with newly diagnosed COPD. We found that patients who underwent testing around the time of diagnosis were $9 \%$ less likely to be admitted to hospital for COPD or die of any cause than were those who did not. The association between pulmonary function testing and better outcomes was significantly influenced by where the condition was diagnosed, with cases diagnosed in the ambulatory care setting $20 \%$ less likely to have an outcome of interest. Although the overall risk reduction was modest, the larger benefit observed in this group, who likely had milder disease, is comparable with that observed with the regular use of some COPD medications. ${ }^{31,32}$ We also found pulmonary function testing to be associated with increased addition of long-acting bronchodilators and long-acting $\beta$-agonist-inhaled corticosteroid medi-

Table 2: Adjusted hazard ratios for death and COPD-related admissions to hospitals and other outcomes associated with peridiagnostic pulmonary function testing in all patients with physician-diagnosed COPD and those diagnosed with COPD in ambulatory care and hospital settings

\begin{tabular}{|c|c|c|c|c|c|c|c|}
\hline \multirow[b]{2}{*}{ Outcome } & \multicolumn{2}{|c|}{$\begin{array}{l}\text { With peridiagnostic testing } \\
\qquad n=28386\end{array}$} & \multicolumn{2}{|c|}{$\begin{array}{l}\text { Without peridiagnostic testing } \\
\qquad n=40512\end{array}$} & \multirow{2}{*}{$\begin{array}{l}\text { Unadjusted risk } \\
\text { difference in outcome } \\
\text { at } 3 \mathrm{yr}, \%(95 \% \mathrm{Cl}) \dagger\end{array}$} & \multicolumn{2}{|c|}{ Adjusted regression } \\
\hline & $\begin{array}{c}\text { Had } \\
\text { outcome, } \%\end{array}$ & $\begin{array}{l}\text { Time to outcome, } \\
\text { d, median (IQR)* }\end{array}$ & $\begin{array}{c}\text { Had } \\
\text { outcome, } \%\end{array}$ & $\begin{array}{l}\text { Time to outcome, } \\
\text { d, median (IQR)* }\end{array}$ & & $\begin{array}{l}\text { Adjusted HR } \\
\text { (95\% CI) } ¥\end{array}$ & $p$ value§ \\
\hline \multicolumn{8}{|l|}{ All patients } \\
\hline $\begin{array}{l}\text { Hospital admission for COPD or } \\
\text { death from any cause }\end{array}$ & 30.9 & $1001(562-1504)$ & 43.5 & $936(398-1468)$ & $10.4(9.7-11.2)$ & $0.91(0.89-0.94)$ & $<0.001$ \\
\hline $\begin{array}{l}\text { Hospital admission for COPD or a } \\
\text { related respiratory disease } 1 \text { or } \\
\text { death from any cause }\end{array}$ & 33.1 & $974(527-1483)$ & 45.9 & $895(354-1440)$ & $10.5(9.8-11.3)$ & $0.92(0.89-0.94)$ & $<0.001$ \\
\hline $\begin{array}{l}\text { Hospital admission for any reason } \\
\text { or death from any cause }\end{array}$ & 53.3 & $705(224-1223)$ & 65.9 & $524(104-1091)$ & $11.7(10.9-12.5)$ & $0.91(0.89-0.93)$ & $<0.001$ \\
\hline Death from any cause & 22.6 & $1098(684-1576)$ & 35.9 & $1043(560-1553)$ & $11.0(10.3-11.7)$ & $0.87(0.84-0.90)$ & $<0.001$ \\
\hline \multicolumn{8}{|c|}{ COPD diagnosed in the ambulatory care setting } \\
\hline $\begin{array}{l}\text { Hospital admission for COPD or } \\
\text { death from any cause }\end{array}$ & 23.0 & 1061 (651-1546) & 30.7 & 994 (547-1498) & $7.01(7.01-7.02)$ & $0.80(0.76-0.84)$ & $<0.001$ \\
\hline $\begin{array}{l}\text { Hospital admission for COPD or a } \\
\text { related respiratory disease or death } \\
\text { from any cause }\end{array}$ & 24.9 & 1037 (629-1533) & 32.8 & $969(511-1476)$ & $7.08(7.07-7.09)$ & $0.80(0.76-0.83)$ & $<0.001$ \\
\hline $\begin{array}{l}\text { Hospital admission for any reason } \\
\text { or death from any cause }\end{array}$ & 44.6 & $810(361-1320)$ & 51.4 & $717(244-1218)$ & $7.11(7.10-7.12)$ & $0.82(0.79-0.85)$ & $<0.001$ \\
\hline Death from any cause & 16.1 & 1131 (715-1595) & 25.1 & $1058(638-1544)$ & $8.16(8.16-8.17)$ & $0.72(0.69-0.76)$ & $<0.001$ \\
\hline \multicolumn{8}{|c|}{ COPD diagnosed in the hospital setting } \\
\hline $\begin{array}{l}\text { Admission to hospital for COPD or } \\
\text { death from any cause }\end{array}$ & 49.8 & $839(304-1402)$ & 53.5 & $882(283-1442)$ & $1.06(1.04-1.07)$ & $1.05(1.01-1.09)$ & 0.02 \\
\hline $\begin{array}{l}\text { Admission to hospital for COPD or } \\
\text { a related respiratory disease or } \\
\text { death from any cause }\end{array}$ & 52.7 & $804(268-1366)$ & 56.1 & $841(242-1413)$ & $0.79(0.78-0.80)$ & $1.06(1.02-1.10)$ & 0.005 \\
\hline $\begin{array}{l}\text { Admission to hospital for any } \\
\text { reason or death from any cause }\end{array}$ & 74.3 & $365(69-936)$ & 77.3 & $344(61-967)$ & $1.22(1.21-1.23)$ & $1.02(0.99-1.05)$ & 0.3 \\
\hline Death from any cause & 38.3 & $1016(534-1520)$ & 44.3 & $1031(472-1564)$ & $3.73(3.71-3.74)$ & $1.03(0.99-1.08)$ & 0.1 \\
\hline \multicolumn{8}{|c|}{$\begin{array}{l}\text { Note: } \mathrm{Cl}=\text { confidence interval, } \mathrm{COPD}=\text { chronic obstructive pulmonary disease, } \mathrm{HR}=\text { hazard ratio, IQR = interquartile range. } \\
\text { ^Time until } 50 \% \text { of patients experienced the event derived from Kaplan-Meier survival curves. } \\
\text { †For each group (testing and nontesting), the unadjusted estimated survival at } 3 \text { years, along with the standard error of the estimate, was obtained using a Kaplan-Meier analysis. The risk } \\
\text { difference for the outcome is the difference between the unadjusted estimated survivals at } 3 \text { years. The variance of this difference is the sum of the variances of the individual measures. } \\
\text { †Reflects the risk in the group with pulmonary function testing compared with the group without pulmonary function testing. Hazard ratios are adjusted for propensity score, } \\
\text { pulmonary function testing before and after the peridiagnostic period, age, sex, whether patients were ambulatory or in hospital for COPD in the peridiagnostic period, asthma and } \\
\text { hospital admission within the previous } 6 \text { months for a COPD-related disease. } \\
\text { §Testing the hypothesis that the hazard ratio is equal to } 1.00 \text {. } \\
\text { IPneumonia, influenza or acute bronchitis. }\end{array}$} \\
\hline
\end{tabular}


cations, which offers a plausible mechanism by which testing might have led to better health outcomes.

Patients who received their diagnosis in the ambulatory care setting may have derived greater benefits from pulmonary function testing because they had more lung function to preserve through good COPD management and were less likely to die or be admitted to hospital overall. Alternatively, unmeasured confounding might explain this finding (although we believe this unlikely for the reasons outlined below), as well as the worse outcomes found in the admitted group who received testing.

Our results support the commonly held understanding that pulmonary function testing is key to the accurate diagnosis and quality care of COPD., ${ }^{3,49}$ Our findings are consistent with literature showing an association between pulmonary function testing and increased use of COPD medication and other interventions. ${ }^{11,12,14,15}$ Our study extends these findings by showing an association between pulmonary function testing and morbidity and mortality.

\section{Limitations}

Our validated case-definition of physician-diagnosed COPD has a specificity of $95 \%$ and positive predictive value of $81 \%$ compared with a clinical reference standard, ${ }^{19}$ so misclassification may have occurred and biased our results. However, the disease most often misclassified as COPD is asthma, which is associated with better health outcomes. ${ }^{33,34}$ Because misclassification was more likely in the group of patients who did not undergo testing, this would have biased our results toward better outcomes in this group, yet we observed the opposite. Furthermore, our sensitivity analyses showed that only under unlikely conditions would misclassification render our findings null in patients who were ambulatory in the peridiagnostic period.

Variables not available in health administrative data, such as lung function or smoking, create potential for unmeasured confounding. However, we used propensity score adjustment and matching to control for a large number of prognostically important variables, many of which are highly correlated with these 2 variables. We also performed a sensitivity analysis taking into account smoking and other variables from a population health survey and found little difference. Finally, our sensitivity analyses showed that the significant results seen in those who were ambulatory in the peridiagnostic period were not easily explained by an unmeasured confounder.

An association between pulmonary function testing and patient outcomes does not prove causation. It is possible that testing was a marker of overall quality of care rather than a direct source of improved outcomes. Trying to tease apart the effects of testing and other good-quality COPD care is challenging because they are likely to be highly correlated. Nonetheless, a positive association was found even after clustering by primary care physician; adjusting for many markers of good quality COPD care (that were highly correlated with pulmonary function testing) such as influenza vaccination, specialist visits and primary ambulatory care visits; and adjusting for markers of quality overall care such as glucose and cholesterol testing.

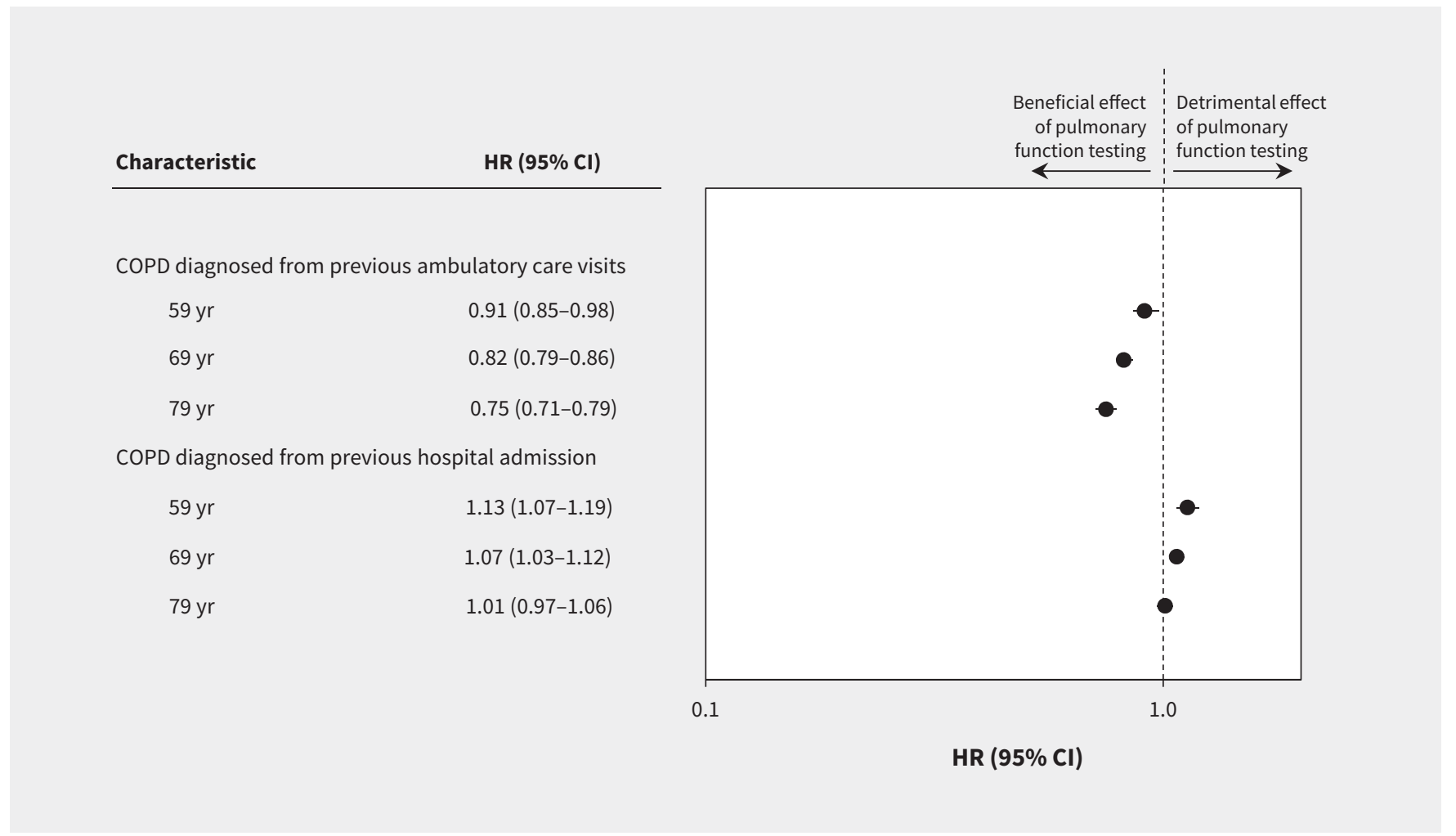

Figure 2: Adjusted effect of peridiagnostic pulmonary function testing on risk of death or admission to hospital for COPD, by whether patients were ambulatory or admitted to hospital for COPD in the peridiagnostic period and by age. Error bars indicate $95 \%$ confidence intervals. $\mathrm{Cl}=$ confidence interval, $\mathrm{COPD}=$ chronic obstructive pulmonary disease, $\mathrm{HR}=$ hazard ratio. 


\section{Medication added to treatment}

\section{Medication}

Overall

Long-acting anticholinergic

Long-acting $\beta$ agonist

Long-acting $\beta$ agonist and inhaled corticosteroid combination

Inhaled corticosteroid

\section{COPD diagnosed in the ambulatory care setting}

Long-acting anticholinergic
Patients with peridiagnostic pulmonary function testing, $\%$
Patients without peridiagnostic pulmonary function testing, $\%$ $p$ value

25.4

$<0.001$

3.0

1.8

$<0.001$

$<0.001$
$<0.001$

44.1

21.0

$<0.001$

2.7

1.1

$<0.001$

Long-acting $\beta$ agonist and inhaled corticosteroid combination

Inhaled corticosteroid

\section{COPD diagnosed in the hospital setting}

Long-acting anticholinergic

Long-acting $\beta$ agonist

Long-acting $\beta$ agonist and inhaled corticosteroid

\section{Inhaled corticosteroid}

Note: $\mathrm{COPD}=$ chronic obstructive pulmonary disease.

*A medication was considered to be newly added to a patient's treatment if there were no prescriptions for the medication in the year before the pulmonary function test date or its equivalent, and at least 1 prescription for it in the year after the pulmonary function test date.

†For patients with pulmonary function testing (cases), the pulmonary function test date was the date on which they received their pulmonary function test. For patients without pulmonary function testing (controls), the pulmonary function test equivalent date was determined by calculating the number of days between the pulmonary function test and the index date of their matched case and then counting back that number of days from their index date.

Finally, we examined the empiric impact of having pulmonary function testing, but could not discern if physicians acted on good-quality tests in an appropriate manner because the results were not known. However, failure of them to do so would have biased our results toward finding no association between testing and outcomes, yet an association was found. In addition, we only examined pulmonary function testing used for diagnosis. Future studies should examine the value of ongoing testing as monitoring for people with COPD.

\section{Conclusion}

The use of pulmonary function testing in the diagnostic workup of people with physician-diagnosed COPD is associated with a decreased risk of admission to hospital for COPD or death in the ambulatory care setting. Given low rates of testing, these findings point to an opportunity to improve patient outcomes, reduce health services use and decrease health care costs by increasing rates of testing for suspected COPD.

\section{References}

1. Lozano R, Naghavi M, Foreman K, et al. Global and regional mortality from 235 causes of death for 20 age groups in 1990 and 2010: a systematic analysis for the Global Burden of Disease Study 2010. Lancet 2012;380:2095-128.

2. Buist AS, McBurnie MA, Vollmer WM, et al.; BOLD Collaborative Research Group.
International variation in the prevalence of COPD (the BOLD Study): a populationbased prevalence study. Lancet 2007;370:741-50.

3. Global strategy for the diagnosis, management, and prevention of chronic obstructive pulmonary disease (updated 2015). Global Initiative for Chronic Obstructive Lung Disease (GOLD); 2015.

4. O’Donnell DE, Hernandez P, Kaplan A, et al. Canadian Thoracic Society recommendations for management of chronic obstructive pulmonary disease -2008 update - highlights for primary care. Can Respir J 2008;15(Suppl A):1A-8A

5. Lee TA, Bartle B, Weiss KB. Spirometry use in clinical practice following diagnosis of COPD. Chest 2006;129:1509-15.

6. Arne M, Lisspers K, Ställberg B, et al. How often is diagnosis of COPD confirmed with spirometry? Respir Med 2010;104:550-6.

7. Han MK, Kim MG, Mardon R, et al. Spirometry utilization for COPD: how do we measure up? Chest 2007;132:403-9.

8. Gershon AS, Hwee J, Croxford R, et al. Patient and physician factors associated with pulmonary function testing for COPD: a population study. Chest 2014;145:272-81.

9. Qaseem A, Wilt TJ, Weinberger SE, et al. Diagnosis and management of stable chronic obstructive pulmonary disease: a clinical practice guideline update from the American College of Physicians, American College of Chest Physicians, American Thoracic Society, and European Respiratory Society. Ann Intern Med 2011;155:179-91.

10. Lusuardi M, De Benedetto F, Paggiaro P, et al. A randomized controlled trial on office spirometry in asthma and COPD in standard general practice: data from spirometry in Asthma and COPD: a comparative evaluation Italian study. Chest 2006;129:844-52.

11. Yawn BP, Enright PL, Lemanske RF Jr, et al. Spirometry can be done in family physicians' offices and alters clinical decisions in management of asthma and COPD. Chest 2007;132:1162-8.

12. Joo MJ, Au DH, Lee TA. Use of spirometry in the diagnosis of chronic obstruc tive pulmonary disease and efforts to improve quality of care. Transl Res 2009; 154:103-10. 
13. Abramson MJ, Schattner RL, Sulaiman ND, et al. Do spirometry and regular follow-up improve health outcomes in general practice patients with asthma or COPD? A cluster randomised controlled trial. Med J Aust 2010;193:104-9.

14. Walker PP, Mitchell P, Diamantea F, et al. Effect of primary-care spirometry on the diagnosis and management of COPD. Eur Respir J 2006;28:945-52.

15. Joo MJ, Lee TA, Au DH, et al. Medication use patterns associated with spirometry in diagnosing COPD. COPD 2008;5:360-8.

16. O'Dowd LC, Fife D, Tenhave T, et al. Attitudes of physicians toward objective measures of airway function in asthma. Am J Med 2003;114:391-6.

17. Hux JE, Naylor CD, Fielding DA. The Ontario Drug Benefit Program copayment: its impact on access for Ontario seniors and charges to the program. Toronto: Institute for Clinical Evaluative Sciences in Ontario; 1997.

18. Collins BF, Feemster LC, Rinne ST, et al. Factors predictive of airflow obstruction among veterans with presumed empirical diagnosis and treatment of COPD. Chest 2015;147:369-76.

19. Gershon AS, Wang C, Guan J, et al. Identifying individuals with physician diagnosed COPD in health administrative databases. COPD 2009;6:388-94.

20. Gershon AS, Warner L, Cascagnette P, et al. Lifetime risk of developing chronic obstructive pulmonary disease: a longitudinal population study. Lancet 2011; 378:991-6.

21. Reid RJ, MacWilliam L, Verhulst L, et al. Performance of the ACG case-mix system in two Canadian provinces. Med Care 2001;39:86-99.

22. Bice TW, Boxerman SB. A quantitative measure of continuity of care. Med Care 1977;15:347-9.

23. PCCF+ version $4 D$ user's guide. Automated geographic coding based on the Statistics Canada Postal Code Conversion files, including postal codes to December 2003 [computer program]. Cat. no. 82-F0086-XDB. Ottawa: Statistics Canada; 2004.

24. du Plessis V, Beshiri R, Bollman RD, et al. Definitions of "rural". Rural and Small Town Canada Analysis Bulletin. Cat. no. 21-006-XIE. Ottawa: Statistics Canada; 2001.
25. Genest J, McPherson R, Frohlich J, et al. 2009 Canadian Cardiovascular Society/Canadian guidelines for the diagnosis and treatment of dyslipidemia and prevention of cardiovascular disease in the adult -2009 recommendations. Can J Cardiol 2009;25:567-79.

26. Canadian Diabetes Association Clinical Practice Guidelines Expert Committee Canadian Diabetes Association 2013 clinical practice guidelines for the prevention and management of diabetes in Canada. Can J Diabetes 2013;37(Suppl 1):S1-212.

27. Hansell AL, Walk JA, Soriano JB. What do chronic obstructive pulmonary disease patients die from? A multiple cause coding analysis. Eur Respir J 2003; 22:809-14.

28. Camilli AE, Robbins DR, Lebowitz MD. Death certificate reporting of confirmed airways obstructive disease. Am J Epidemiol 1991;133:795-800.

29. D'Agostino RB Jr. Propensity score methods for bias reduction in the comparison of a treatment to a non-randomized control group. Stat Med 1998;17: 2265-81.

30. Gershon A, Croxford R, To T, et al. Comparison of inhaled long-acting betaagonist and anticholinergic effectiveness in older patients with chronic obstructive pulmonary disease: a cohort study. Ann Intern Med 2011;154:583-92.

31. Calverley P, Pauwels R, Vestbo J, et al. TRial of Inhaled STeroids ANd long-acting beta2 agonists study group. Combined salmeterol and fluticasone in the treatment of chronic obstructive pulmonary disease: a randomised controlled trial. Lancet 2003;361:449-56.

32. Tashkin D, Celli B, Kesten S, et al. Effect of tiotropium in men and women with COPD: results of the 4-year UPLIFT trial. Respir Med 2010;104:1495-504.

33. Gershon AS, Guan J, Wang C, et al. Trends in asthma prevalence from 1996 to 2004: a population-based study. Am J Respir Crit Care Med 2009;179:A4754.

34. Gershon AS, To T, Guan J, et al. Trends in chronic obstructive pulmonary disease (COPD) prevalence, incidence and mortality in Ontario, overall and by LHIN, 1996/97-2009/10. Toronto: Institute for Clinical Evaluative Sciences; 2011.

\section{Competing interests: None declared.}

This article has been peer reviewed.

Affiliations: Institute for Clinical Evaluative Sciences (Gershon, Mecredy, Croxford, To, Stanbrook); Sunnybrook Health Sciences Centre (Gershon); Institute of Health Policy, Management and Evaluation (Gershon, Stanbrook) and Dalla Lana School of Public Health (To) , University of Toronto; The Hospital for Sick Children (To); University Health Network (Stanbrook), Toronto, Ont.; Ottawa Hospital Research Institute (Aaron), University of Ottawa, Ottawa, Ont.

Contributors: All authors participated in the design, analysis and interpretation of the data and critical revision of the manuscript, all approved the final version, and all agreed to be accountable for all aspects of the work.
Andrea Gershon, the corresponding author, had full access to all the data in the study and had final responsibility for the decision to submit for publication. Andrea Gershon, Teresa To, Matthew Stanbrook and Shawn Aaron conceived of the study and Andrea Gershon obtained funding. Andrea Gershon and Graham Mecredy drafted the manuscript. The statistical analyses were performed by Ruth Croxford.

Funding: This study was supported by a grant from the Ontario Lung Association and Pfizer Canada. It also received support from the Institute for Clinical Evaluative Sciences (ICES), which is funded by an annual grant from the Ontario Ministry of Health and LongTerm Care (MOHLTC). The study sponsors had no role in study design; in the collection, analysis, and interpretation of data; in the writing of the report; or in the decision to submit the paper for publication. Andrea Gershon is supported by a Fellowship in Translational Research from The Physicians' Services Incorporated Foundation, Toronto, Ontario, Canada and was supported by New Investigator Award funded by team grant (9 OTG-88591) from the Canadian Institutes of Health Research Institute of Nutrition, Metabolism and Diabetes while working on this study.

Disclaimer: Matthew Stanbrook is a deputy editor for CMAJ and was not involved in the editorial decision-making process for this article.

Accepted: Sept. 14, 2016

Early release: Nov. 14, 2016

Correspondence to: Andrea Gershon, andrea.gershon@ices.on.ca 